\section{Commentary: No free lunch: What we talk about when we talk about anomalous aortic origin of a coronary artery}

\author{
Jonathan M. Chen, MD
}

Paradoxically, one of the most straightforward parental surgical consents is that obtained for an otherwise lethal lesion, no matter how seemingly prohibitive the operative risk. However, for the majority of operations, the discussions of "informed" consent revolve around the tension of operative and perioperative risk as weighed against the natural history of disease progression if left untreated. Although statistical risks of both death or complication can be estimated, none is definitively known for any one patient, and so in truth the choice to proceed with any operation often is as much a decision of faith as of exacting odds. This tension is no better illustrated than in the evolution of surgical intervention for anomalous aortic origin of a coronary artery (AAOCA), a condition for which the "actual" risk of sudden death is inexact, the "true" mechanism of ischemia is unclear, and the long-term preventative impact of surgery is unknown. In this issue of the Journal, Jegatheeswaran and colleagues, ${ }^{1}$ from the Congenital Heart Surgeons' Society, profile the medical and surgical outcomes of 682 patients with AAOCA enrolled over an 8-year period.

Despite an impressive array of data, and even with the extraordinary discipline of a Congenital Heart Surgeons' Society database study, Jegatheeswaran and colleagues' article $^{1}$ brings us only slightly closer to a better understanding of the risk/benefit ratio of intervening on AAOCA. The arc of surgical enthusiasm for this lesion has followed from an initial (naïve?) understanding that an intramural/interarterial/intraconal course could be remedied to (1) the realization that the 2

From the Cardiothoracic Surgery, Children's Hospital of Philadelphia, Philadelphia, $\mathrm{Pa}$.

Disclosures: Author has nothing to disclose with regard to commercial support.

Received for publication Feb 4, 2020; accepted for publication Feb 4, 2020; available ahead of print Feb 14, 2020.

Address for reprints: Jonathan M. Chen, MD, Cardiothoracic Surgery, Children's Hospital of Philadelphia, 3401 Civic Center Boulevard, Suite 8574, Philadelphia, PA 19104 (E-mail: chenj14@email.chop.edu).

J Thorac Cardiovasc Surg 2020;160:774

$0022-5223 / \$ 36.00$

Copyright (c) 2020 by The American Association for Thoracic Surgery

https://doi.org/10.1016/j.jtcvs.2020.02.019

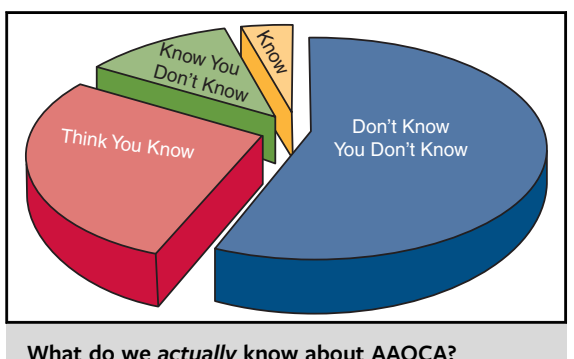

What do we actually know about AAOCA?

CENTRAL MESSAGE

Operations to repair AAOCA are not without consequences, and these must be considered in evaluating the risk/benefit ratio of intervention versus

observation.

indications for operation (prevention of sudden death, resolution of symptoms) are incompletely addressed, and more recently (2) a growing appreciation of significant morbidity that can be incurred even with a "successful" intervention. ${ }^{1-5}$

Jegatheeswaran and colleagues' article $^{1}$ helps us better appreciate the pitfalls of current operative strategies. As their data would suggest, the association of symptoms with bona fide ischemia is less than $50 \%$, the risk of more than mild aortic insufficiency with commissural manipulation is considerable, and for some, there continues to be a need for additional coronary reoperations. ${ }^{1}$ In short, there is no free lunch in cardiac surgery. Of note, of the 287 patients not treated surgically, $6(2.1 \%)$ died of nonAAOCA-related conditions during the study period, which is twice the number whose cause of death was "related to AAOCA." Although only a cheeky congenital surgeon might then deduce that AAOCA is protective from death in the nonoperative cohort, these demographic data highlight the magnitude of our lack of clarity as to the competing risks of death in the general population. In Carver's short story, the nature of love remains elusive despite his character's best efforts to define it. ${ }^{6}$ Unfortunately, except for those who experience arrest as the result of ischemia, the true risk/benefit of operations for AAOCA may be comparably vague for any patient. Our job as a congenital community is to reevaluate our data with vigilance and humility, and remember that in the management of AAOCA, there may be a considerable amount that we don't know that we don't know. 


\section{References}

1. Jegatheeswaran A, Devlin PJ, Williams WG, Brothers JA, Jacobs ML, DeCampli WM, et al. Outcomes after anomalous aortic origin of a coronary artery repair: a Congenital Heart Surgeons' Society Study. J Thorac Cardiovasc Surg. 2020;160:757-71.e5.

2. Mery CM, DeLeon LE, Molossi S, Sexson-Tejtel SK, Agrawal H, Krisnamurthy R, et al. Outcomes of surgical intervention for anomalous aortic origin of a coronary artery: a large contemporary prospective cohort study. $J$ Thorac Cardiovasc Surg. 2018;155:305-19.

3. Sachdeva S, Frommelt MA, Mitchell ME, Tweddell JS, Frommelt PC, Surgical unroofing of intramural anomalous aortic origin of a coronary artery in pediatric patients: single-center perspective. J Thorac Cardiovasc Surg. 2018; 155:1760-8.

4. Nees SN, Flyer JN, Chelliah A, Dayton JD, Touchette L, Kalfa D, et al. Patients with anomalous aortic origin of the coronary artery remain at risk after surgical repair. J Thorac Cardiovasc Surg. 2018;155:2554-64.

5. Jegatheeswaran A, Devlin PJ, McCrindle BW, Williams WG, Jacobs WL, Blackstone E, et al. Features associated with myocardial ischemia in anomalous aortic origin of a coronary artery: a Congenital Heart Surgeons' Society study. $J$ Thorac Cardiovasc Surg. 2019;158:822-34.e3.

6. Carver R. What We Talk About When We Talk About Love. New York: Knopf; 1981.

\title{
Commentary: I guess I'm just confused...isn't this information sobering?
}

\author{
Charles D. Fraser, Jr, MD
}

I have been anxiously waiting for the article by Jegatheeswaran and colleagues ${ }^{1}$ concerning the outcomes after surgery for anomalous aortic origin of a coronary artery (AAOCA) to be published. I was an invited discussant for the oral presentation of these data at the annual meeting of the American Association for Thoracic Surgery almost 1 year ago. At the time, I thought these data needed to be published as soon as possible. In fact, I commented to several colleagues that the accompanying article merited an expedited review. I found the information concerning and critically important to what have become very frequent (and lengthy) conversations with patients and families about AAOCA surgery. Maybe I was confused, but I thought we really need to pay close attention to what is going on with this subject.

The study is not perfect, but what study is? It is a retrospective look at a voluntary registry from 45 centers contributing to the Congenital Heart Surgeons Society. Thus, there must be some selection bias, but I argue that

From the Texas Center for Pediatric and Congenital Heart Disease, Dell Children's Hospital, The University of Texas - Dell Medical School, Austin, Tex.

Disclosures: Author has nothing to disclose with regard to commercial support.

Received for publication Feb 5, 2020; accepted for publication Feb 6, 2020; available ahead of print Feb 14, 2020.

Address for reprints: Charles D. Fraser, Jr, MD, Texas Center for Pediatric and Congenital Heart Disease, Dell Children's Hospital, 4900 Mueller Blvd, Suite 3S.003, Austin, TX 78723 (E-mail: Charles.Fraser@austin.utexas.edu).

J Thorac Cardiovasc Surg 2020;160:775-6

$0022-5223 / \$ 36.00$

Copyright (c) 2020 by The American Association for Thoracic Surgery

https://doi.org/10.1016/j.jtcvs.2020.02.020

this may influence the data toward a more optimistic than practically realistic viewpoint. More to come on that. One criticism of the article was that it does not compare outcomes between surgical and expectant (nonoperative) management. That was not the intention of the study, and, of course, to make such a comparison, one would have to agree to nonoperative treatment of patients with the

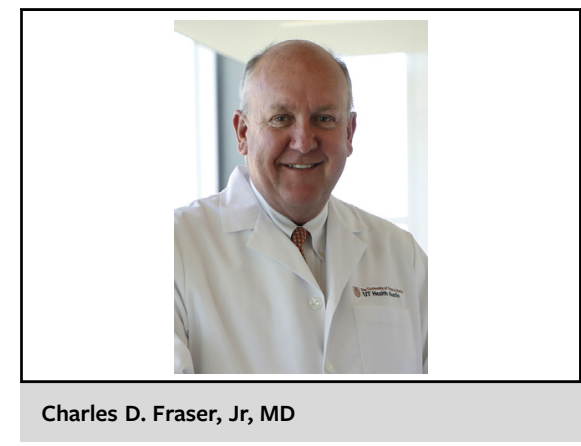

CENTRAL MESSAGE

AAOCA is being diagnosed in many people; some are symptomatic, but most are asymptomatic. Many of these patients end up undergoing cardiac surgery at a time where indications for operation are not completely clear. Are these operations safe? What are the current complication rates? We really have to know, and the data suggest reason for more attention. 